Nippon Suisan Gakkaishi $\quad 58(8), 1511-1516(1992)$

\title{
The Structure of an Extracellular Mucopolysaccharide Produced by a Marine Pseudomonas
}

\author{
Suda Tandavanitj, ${ }^{*}$ Shigeyuki Tajima, ${ }^{*}$ and Koichi Okutani* \\ (Received February 17, 1992)
}

\begin{abstract}
The structure of a highly viscous extracellular mucopolysaccharide produced by a marine bacteria designated strain No. 9-12 which was identified as an oxidase negative Pseudomonas was characterized by means of partial hydrolysis, periodate oxidation and selective cleavages of the polysaccharide chain. The polysaccharide has a branched structure with a backbone chain of -GalUA-GlcNA-GalNAc- and a side chain of GalUA-Gal-GalNAc-. The terminal galacturonic acid residue in the side chain was linked to $D$-alanine via an amide linkage.
\end{abstract}

In 1977, one of the present authors (K. O.) reported the isolation of an antitumor mucopolysaccharide-producing bacterium from seawater. ${ }^{1}$ ) A characteristic feature of this bacterium was the production of a highly viscous extracellular mucopolysaccharide, ${ }^{2)}$ which was composed of galacturonic acid, galactose, glucosamine, galactosamine, alanine, and pyruvate, together with $N$-acetyl groups. ${ }^{3)}$

In this paper we describe further studies of the structure of this extracellular mucopolysaccharide as well as characterization of the bacterium.

\section{Materials and Methods}

\section{Bacterial Taxonomy}

Taxonomic studies were carried out according to the methods described by Baumann et al. ${ }^{4}$ ) and by the method previously described..$^{5}$

\section{Analytical Methods}

The general methods and methods of isolation and purification of the extracellular mucopolysaccharide from Pseudomonas strain No. 9-12 have been described previously. ${ }^{2,3,8)}$

\section{Electron Microscopy}

Cell morphology was observed by electron microscopy. Negatively stained preparations were examined with a Hitachi HU-12A electron microscope.

\section{NMR Spectroscopy}

The $500 \mathrm{MHz}\left({ }^{1} \mathrm{H}\right)$ and $125 \mathrm{MHz}\left({ }^{13} \mathrm{C}\right) \mathrm{NMR}$ spectra were obtained with a JEOL JNM GSX
500 spectrometer at $75^{\circ} \mathrm{C}$.

Selective Cleavages of the Polysaccharide Chain Methanolysis of the Polysaccharide: Methanolysis of the polysaccharide was performed with an acidic dimethylsulfoxide (DMSO) solution by the method of Takada et al. ${ }^{\text {" }}$ with some modifications. The polysaccharide $(100 \mathrm{mg})$ was dissolved in DMSO $(27 \mathrm{ml})$, followed by addition of methanol $(3 \mathrm{~m} /)$ and $\mathrm{H}_{2} \mathrm{SO}_{4}(0.5 \mathrm{ml})$. After reffuxing for 3 days at $70^{\circ} \mathrm{C}$, reaction was terminated by neutralization with $6 \mathrm{~N} \mathrm{NH}_{4} \mathrm{OH}$.

The reaction mixture was freed from methanol, applied to a charcoal-celite $(1: 1)$ column $(2.5 \times$ $15 \mathrm{~cm}$ ), and eluted in steps with $1 l$ each of water, 5,10 , and $15 \%$ ethanol at a flow rate of $5 \mathrm{~m} / \mathrm{h}$. Fractions were then separated by chromatography on a Bio-Gel P 2 column $(2.5 \times 90 \mathrm{~cm})$ with water: pyridine: acetic acid $(500: 5: 2)$ at a flow rate of $5.5 \mathrm{~m} / 30 \mathrm{~min}$. Eluates were assayed by the phenol-sulfuric acid method, ${ }^{8)}$ and carbohydrate-containing fractions were lyophilized. Oligosaccharides which were obtained by a Bio-Gel P 2 column were further fractionated by HPLC or Amberlite IR-410 resin. HPLC was performed on a Wakopak WBT $130 \mathrm{E}$ column $(7.8 \times 300 \mathrm{~mm})$ by using RI detector and water as a mobile phase at $60^{\circ} \mathrm{C}$ and a flow rate of $0.5 \mathrm{~m} l /$ $\min$.

Partial Acid Hydrolysis: The polysaccharide (100 mg) was hydrolyzed with $2 \mathrm{M}$ TFA $(20 \mathrm{ml})$ for $12 \mathrm{~h}$ at $100^{\circ} \mathrm{C}$. The reaction mixture was repeatedly evaporated with water under diminished pressure, and passed through a column of Amberlite IR-410 resin (formate form). Acidic sugars

* Faculty of Agriculture, Kagawa University, Miki, Kida, Kagawa 761-07, Japan (S. Tandavanitj, 田泉茂 行, 奥谷康一: 香川大学塐学部). 
were eluted from the resin with $10 \%$ formic acid, followed by fractionation on a Bio-Gel $\mathbf{P} 2$ column.

\section{Periodate Oxidation}

Periodate oxidation and subsequent Smith hydrolysis were conducted as described previously. ${ }^{9)}$

\section{$N$-Deacetylation}

$N$-Deacetylation of the polysaccharide was accomplished with hot alkaline solution and the purified preparation was obtained from DEAEcellulose column chromatography as described previously. ${ }^{3)}$ The product was partially $N$ deacetylated and was free of alanine and pyruvate. ${ }^{\beta)}$

\section{Borohydride Reduction of Oligosaccharide}

A portion of the oligosaccharide was treated with $5 \%$ methanolic hydrogen chloride, and the mixture was neutralized with silver carbonate. The reaction mixture was treated with sodium borohydride in anhydrous methanol to obtain reduction products of uronic acids.

\section{Estimation of Molecular Weight}

Average molecular weight was determined by HPLC by using GPC on an Asahipak GFA $7 \mathrm{M}$ column (Asahi Chemicals, $7.6 \times 500 \mathrm{~mm}$ ) as described previously. ${ }^{2}$ A Shodex Standard Kit P-82 (Showa Denko) was used for calibration of molecular size.

\section{Results and Discussion}

Figure 1 shows an electron micrograph of the

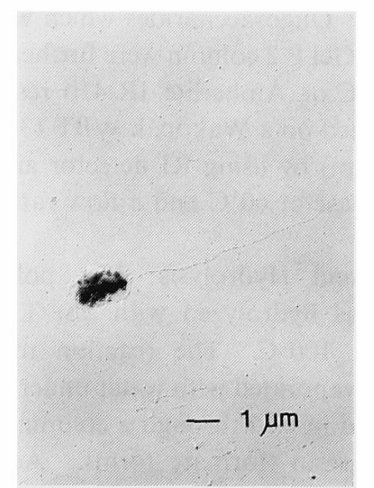

Fig. 1. Electron micrograph of Pseudomonas sp., strain No. 9-12 $(\times 4,000)$.
Table 1. Characteristics of the strain

\begin{tabular}{lc}
\hline \multicolumn{1}{c}{ Characteristics } & Isolate \\
\hline Indole production & - \\
Voges Proskauer & - \\
Oxidase (Kovac's) & - \\
Gram stain & - \\
Spores & - \\
Motility $\left(25^{\circ}\right)$ & + \\
Glucose OF medium & O
\end{tabular}

Growth in reduced oxygen Obligately aerobic

Hydrolysis of

Gelatin

Casein

Starch

Urea

Tween 80

DNA

Aesculin

Lysine decarboxylase $\quad(+)$

Arginine dihydrolase $\quad(+)$

Ornithine decarboxylase -

$\mathrm{H}_{2} \mathrm{~S}$ production

$\beta$-galactosidase -

Nitrate reduction -

Assimilation of

D-glucose

D-Arabinose

L-Arabinose

D-Mannose

Mannitol

$\mathrm{N}$-acetyl-D-glucosamine

Maltose

Gluconate

Caprate

Adipate

Malate

Citrate

Phenylacetate

Arginine

Betaine

Lactate

Acetate

$\mathrm{Mol} \% \mathrm{G}+\mathrm{C}$ of DNA

Growth at

$37^{\circ} \mathrm{C}$

$41^{\circ} \mathrm{C}$

Growth in

$0 \% \mathrm{NaCl}$

$2 \% \mathrm{NaCl}$

$10 \% \mathrm{NaCl}$

Sensitivity to

$\mathrm{O} / 129$

Penicillin

Streptomycin

Chloramphenicol

Tetracycline

Novobiocin

Polymyxin

-
-
-
-
+
-
-
+
+
-
+
-
-
+
-
-
+
+
+
+
+
+
+
+
+
+
+
+
+
+
+
+
+
+
+
+
+
+
+
+
+
+
+
+
+
+
+

Pigment in King's B medium Greenish yellow

+ , Positive reaction; - , negative reaction; $(+)$, weakly positive reaction. 
marine bacterium strain No. 9-12. The characteristics of this strain are listed in Table 1. The isolate is a Gram negative straight rod (0.6$0.8 \times 1.0-1.5 \mu \mathrm{m})$; it is asporogenous, motile by means of a polar flagellum, and obligately aerobic. It grows oxidatively on an OF medium. It does not produce oxidase but produces a greenish yellow pigment on the surface of King's B medium prepared with seawater. Except for the oxidase reaction, these characteristics correspond with those of Pseudomonas, according to general bacteriology manuals. ${ }^{10)}$

Oxidase negative strains of Pseudomonas were listed among the aerobic marine eubacteria studied by Baumann et al. ${ }^{\text {) }}$ However, the present isolate differs from strains studied by them in some important biochemical reactions such as the production of lipase and the assimilation of maltose, acetate, $\mathrm{N}$-acetylglucosamine, L-arginine, and betaine. We consider that it is probably one of the oxidase-negative Pseudomonas, but it does not fit well with any of the described species. The fact that this isolate grows well on a medium prepared with seawater and can grow at $10 \% \mathrm{NaCl}$ indicates that this isolate is a marine strain.

\section{NMR Spectroscopy}

The ${ }^{1} \mathrm{H}$ and ${ }^{13} \mathrm{C}$ NMR spectra of the polysaccharide revealed methyl signals at $\delta_{\mathrm{B}} 2.06,2.02$, and 1.90 , and at $\delta_{c} 24.6,24.9$, and 25.2 , indicating the presence of $N$-acetylated amino sugar res- idues $^{11-13)}$ (Fig. 2). The signal at $\delta_{\mathrm{c}} 26.2$ disappeared upon depyruvation, thereby suggesting the presence of acetal-linked pyruvic acid..$^{14,15)}$ The signals at $\delta_{\mathrm{H}} 1.45, \delta_{\mathrm{c}} 20.5$, and 53.1 suggest the presence of alanine. ${ }^{16-18)}$ The signals at $\delta_{\mathrm{C}} 52.5,54.4$, and 56.3 indicate the presence of carbons linked to nitrogen, suggesting the presence of amino sugars. ${ }^{18)}$ No signals attributable to $O$-acetyl groups were observed in the NMR spectra. ${ }^{11}$

The ${ }^{13} \mathrm{C}$ NMR spectrum showed anomeric signals at $\delta 105.4\left({ }^{1} \mathrm{~J}_{\mathrm{CH}} 160.2 \mathrm{~Hz}\right), 105.2\left({ }^{1} \mathrm{~J}_{\mathrm{HH}}\right.$ $160.2 \mathrm{~Hz}), \quad 104.4 \quad\left({ }^{1} \mathrm{~J}_{\mathrm{CH}} 158.7 \mathrm{~Hz}\right), \quad 101.4 \quad\left({ }^{1} \mathrm{~J}_{\mathrm{CH}}\right.$ $177.0 \mathrm{~Hz}), 99.1\left({ }^{1} \mathrm{~J}_{\mathrm{CH}} 177.0 \mathrm{~Hz}\right)$, and $99.0\left({ }^{1} \mathrm{~J}_{\mathrm{CH}}\right.$ $175.2 \mathrm{~Hz}$ ), and a C-2 of pyruvate at $110.3,{ }^{(8)}$ indicating that the polysaccharide has a regular structural feature of hexasaccharide-repeating units. The three of these with ${ }^{1} \mathrm{~J}_{\mathrm{CH}}$ values under $170 \mathrm{~Hz}$ can be assigned to $\beta$-linked glyco configurations and the remaining to $\alpha$-linked glyco configurations. ${ }^{20)}$ Each repeating unit contains pyruvic acid and the amino sugar residues are $\mathrm{N}$-acetylated.

\section{Selective Cleavages of the Polysaccharide}

Methanolysis: Cleavages of the glycosidic linkage at the $\mathrm{N}$-acetylated hexosamine residue were specifically performed by methanolysis in an acidic DMSO solution.? The methanolysis products were fractionated on charcoal-celite, followed by gel filtration on a Bio-Gel P 2 .

Fraction M-1 shown in Fig. 3 was eluted in

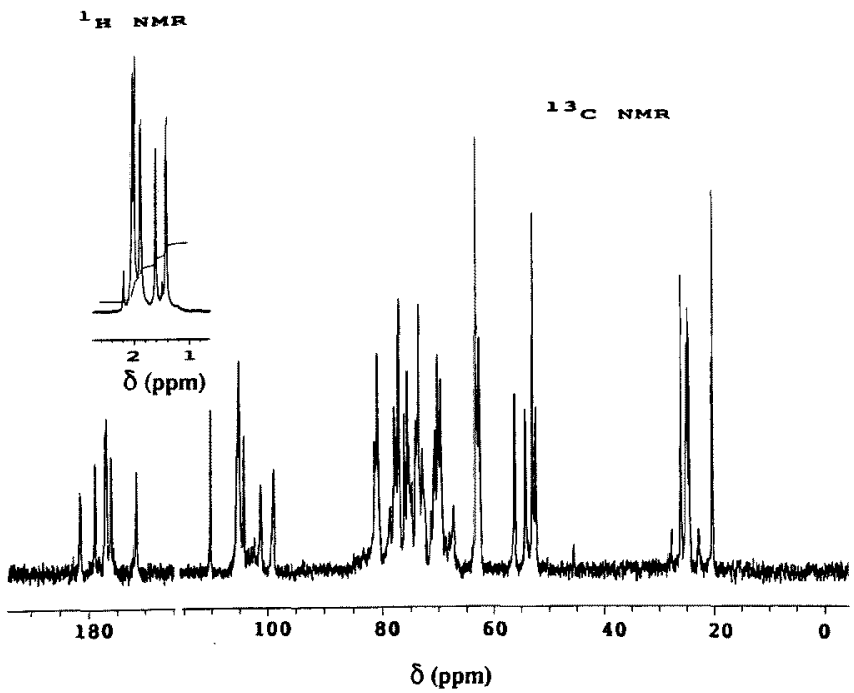

Fig. 2. ${ }^{1} \mathrm{H}$ and ${ }^{13} \mathrm{C}$ NMR spectra of the polysaccharide in $\mathrm{D}_{2} \mathrm{O}$. 
(A) $5 \% \mathrm{EtOH}$

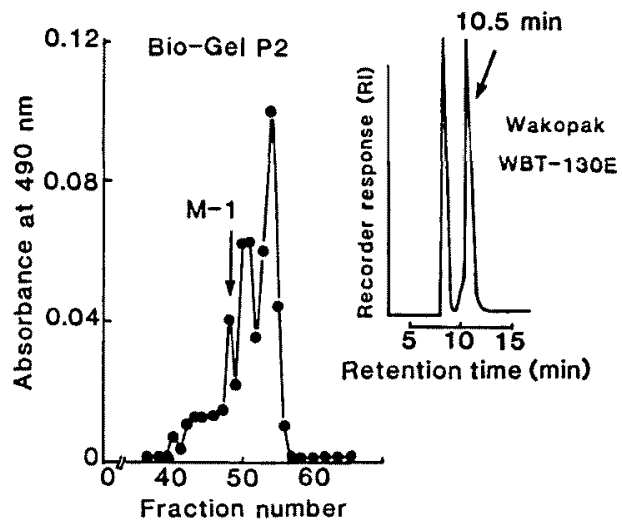

(C) $15 \% \mathrm{EtOH}$

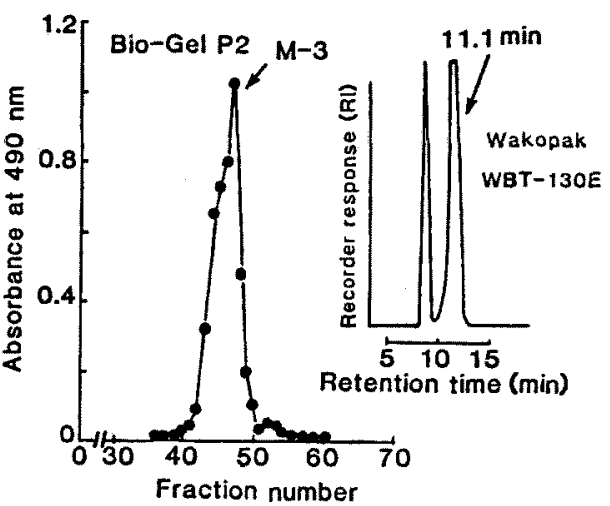

(B) $10 \% \mathrm{EtOH}$

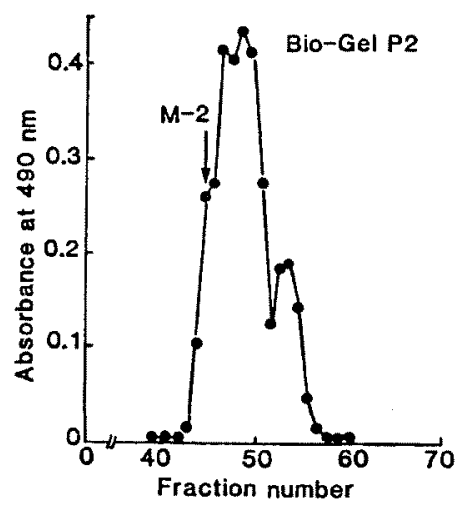

Fig. 3. Elution profiles of the methanolyzates on a BioGel P2 column after fractionation on a charcoal-celite column with ethanol concentrations of 5,10 , and $15 \%$.

Fractions M-1 (Fr. No. 47-49) in Fig. 3A and M-3 (Fr. No. 46-51) in Fig. 3C which were obtained on a Bio-Gel P2 column were collected and freeze-dried and then isolated by HPLC on a Wakopak WBT $130 \mathrm{E}$ column. The peaks with Rt 10.5 and $11.1 \mathrm{~min}$ on HPLC were collected to yield purified products of fractions $M-1$ and $M-3$, respectively. Fraction $M-2$ (Fr. No. 42-45) in Fig. 3B was further separated by using Amberlite IR-410 resin (formate form) and the acidic fraction was collected to yield the purified fraction $\mathrm{M}-2$. the region chracteristic of disaccharide on a Bio Gel P2, and further purified by HPLC on a Wakopak WBT $130 \mathrm{E}$. The peak with Rt 10.5 $\min$ was homogeneous in electrophoresis, and gave galacturonic acid and glucosamine on hydrolysis. This also gave galactose and glucosamine in the molar ratio of $1: 1$ on hydrolysis after reduction with sodium borohydride, thus suggesting that this disaccharide is GalUAGlcNAc.

Eluate with $10 \%$ EtOH from a charcoal-celite column gave fraction $\mathrm{M}-2$ in Bio-Gel P 2 gel filtration, which corresponded to the region characteristic of trisaccharide (Fig. 3 B). It was further fractionated on Amberlite IR 410 resin (formate form) into acidic and neutral fractions. The acidic fraction was homogeneous in electrophoresis and gave galacturonic acid, galactose, and galactosamine upon hydrolysis. It also gave galactose and galactosamine in the molar ratio of $2: 1$ on hydrolysis after carboxyl reduction by sodium borohydride, thus suggesting that this trisaccharide is GalUA-GalGalNAc.

Eluate with $15 \%$ EtOH from the charcoalcelite column gave fraction $\mathrm{M}-3$ in a Bio-Gel P 2 gel filtration (Fig. $3 \mathrm{C}$ ). It was purified by HPLC on a Wakopak WBT $130 \mathrm{E}$. The peak with Rt 11.1 min was homogeneous in electrophoresis and gave galactose and galactosamine in the molar ratio of $1: 1$ on hydrolysis, suggesting that this disaccharide is Gal-GalNAc.

Partial hydrolysis: As shown in Fig. 4, the acidic fraction of partial hydrolyzates gave 3 major peaks in gel filtration on Bio-Gel $\mathbf{P} 2$, of which fraction A-1 was homogeneous both in electrophoresis and GPC on Asahipak GFA $7 \mathrm{M}$. Its molecular weight was estimated to be 440. Hydrolysis of A-1 with $2 \mathrm{M}$ TFA for $12 \mathrm{~h}$ at $100^{\circ} \mathrm{C}$ gave alanine, galacturonic acid, ga- 


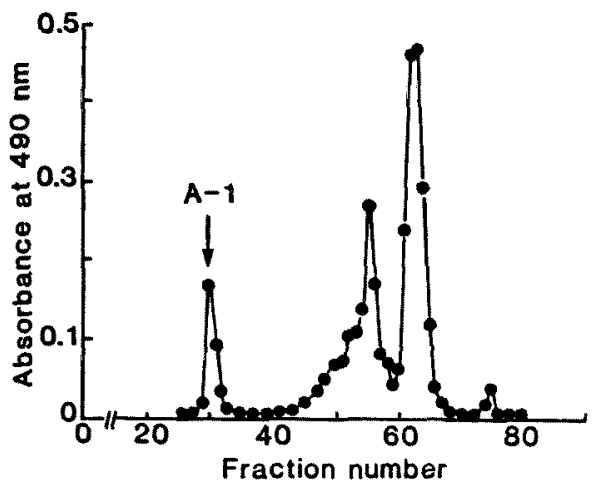

Fig. 4. Elution profile of the partial acid hydrolyzate on a Bio-Gel P2 column.

lactose, and a disaccharide. The disaccharide was purified by preparative paper chromatography $\left(R_{\text {gic }}=0.66\right)$. The purified material gave galacturonic acid and galactose on hydrolysis. Thus, the disaccharide is an aldobiouronic acid, GalUA-Gal.

As described before, alanine is covalently attached to the carboxyl group of the uronic acid residue in this polysaccharide chain. ${ }^{3)}$ Thus, it is suggested that A-1 has the following structure: Ala

GaIUA-Gal

\section{Periodate Oxidation}

The partially $N$-deacetylated polysaccharide was oxidized by periodate as described previous- ly. ${ }^{\theta)}$ The major polymeric material (M.W.= $5.0 \times 10^{4}$ ) which remained after Smith hydrolysis was composed of equimolar amounts of galacturonic acid, glucosamine, and galactosamine.

The 'H NMR spectrum of this product showed anomeric signals at $\delta 5.42(1 \mathrm{H}$, unresolved) and 5.34 (2 H, unresolved) (Fig. 5). Similarly, the ${ }^{13} \mathrm{C}$ NMR spectrum showed three anomeric signals at $\delta 104.1,103.1$, and 101.0.

Signals at $\delta_{\mathrm{I}} 2.01$ and 1.94, and at $\delta_{0} 23.3$ and 23.0 indicate the presence of $N$-acetyl groups. ${ }^{11-13)}$ Signals at $\delta_{\mathrm{c}} 54.9$ and 52.0 indicate the presence of the carbons linked to nitrogen, probably amino groups of amino sugars. ${ }^{18)}$ Signals at $\delta_{\mathrm{o}} 176.0$, 175.3, and 175.1 are attributable to carbonyl groups, assuming one carboxyl and two acetyl groups.

These data suggest that the main chain of the polysaccharide which remained after Smith hydrolysis has a regular structural feature of trisaccharide repeating units, involving two amino sugars which are $\mathrm{N}$-acetylated.

Combined results indicate that the product formed after the Smith hydrolysis has the following structure: -GalUA-GlcNAc-GalNAc-.

This polymer was resistant to the second periodate oxdation, suggesting that the galacturonic acid residue has a $\mathrm{C}-3$ linkage, whereas the amino sugar residues have $\mathrm{C}-3$ or $\mathrm{C}-4$ linkages.

The product released from the main chain of the polysaccharide by the Smith hydrolysis gave galactose on hydrolysis, indicating that the galactose residue is resistant to periodate oxidation.

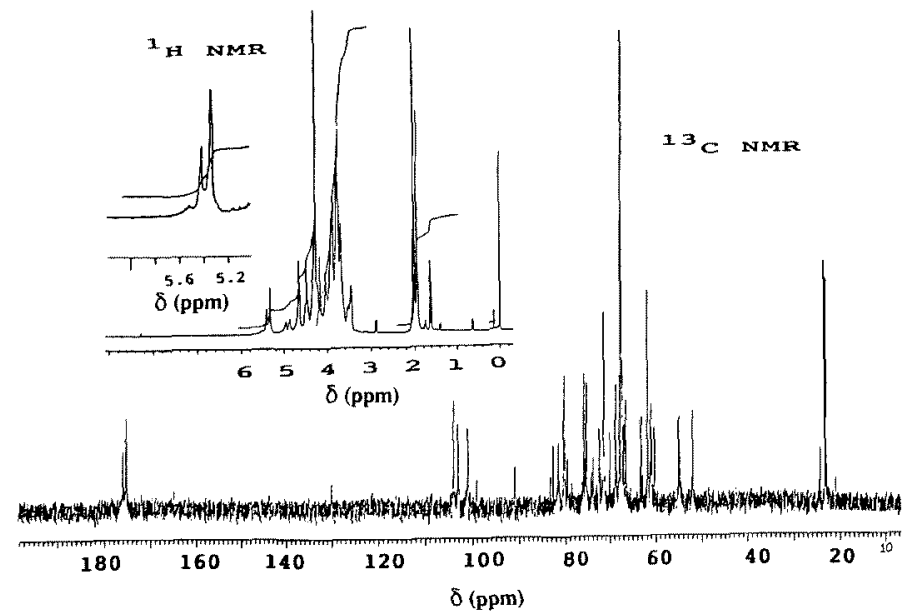

Fig. 5. ${ }^{1} \mathrm{H}$ and ${ }^{13} \mathrm{C}$ NMR spectra of the Smith degradation product of the partially $\mathrm{N}$-deacetylated polysaccharide in $\mathrm{D}_{2} \mathrm{O}$. 
Combined results with periodate oxidation and the selective cleavages of the polysaccharide by methanolysis and partial hydrolysis show that the polysaccharide has a branched structure containing a backbone chain of -GalUAGlcNAc-GalNAc- and a side chain of GalUAGal-GalNAc-. The terminal galacturonic acid in the side chain linked a D-alanine by an amide linkage. ${ }^{\circ)}$

Further studies of the structure of this polysaccharide, including the linkage position of pyruvic acid to the sugar moeity, are in progress by using the techniques of methylation and NMR spectroscopy.

\section{Acknowledgments}

We thank Dr. T. Yoshikumi of the Kureha Chemical Co. for the NMR measurements. We are also grateful to Dr. E. Miki and Dr. T. Tokuda of Kagawa University for operating the electron microscope.

\section{References}

1) K. Okutani: A viscous antitumor substance obtained from a marine bacterium No. 9-12. Nippon Suisan Gakkaishi, 43, 323 328 (1977).

2) S. Tandavanitj, E. Miki, and K. Okutani: The flow properties of an extracellular mucopolysaccharide produced by a marine strain of Pseudomonas. Nippon Suisan Gakkaishi, 56, 1865-1869 (1990).

3) S. Tandavanitj, S. Ishida, and K. Okutani: Isolation and characterization of an extracellular mucopolysaccharide produced by a marine strain of Pseudomonas. Nippon Suisan Gakkaishi, 55, 2015-2019 (1989).

4) L. Baumann, P. Baumann, M. Mandel, and R. D. Allen: Taxonomy of aerobic marine eubacteria. J. Bacteriol, 110 , $402-429$ (1972).

5) K. Okutani: Taxonomical studies of a polysaccharideproducing bacterium from sea cucumber, Stichopus japonicus (SELENKA). Tech. Bull. Fac. Agr. Kagawa Univ., 36, 135140 (1985).

6) S. Tandavanitj and K. Okutani: Partial structure of an extracellutar mucopolysaccharide produced by a marine bacterium. Nippon Sulsan Gakkaisht, 56, 2103-2107 (1990).

7) H. Takada, Y. Araki, and E. Ito: Structure of polygalactosamine produced by Aspergillus parasiticus. J. Biochem., 89, 1265-1274 (1981).

8) M. Dubois, K. A. Gilles, J. K. Hamilton, P. A. Rebers, and F. Smith: Colorimetric method for determination of sugars and related substances. Anal. Chem., 28, 350-356 (1950).

9) S. Tandavanitj and K. Okutani: The structural investigation of a sulfated polysaccharide produced by a strain of marine Pseudomonas. Nippon Suisan Gakkaishi, 55, 1845-1849 (1989).

10) D. J. Brenner: in "Bergey's Manual of Systematic Bacteriology" (ed. by N. R. Krieg and J. G. Holt) Vol. 1, Williams and Wilkins, London, 1984, pp. 140-406.

11) Y. A. Knirel, V. V. Dashunin, A. S. Shashkov, N. K. Kochetkov, B. A. Dmitriev, and I. L. Hofman: Somatic antigens of Shigella: structure of the $O$-specific polysaccharide chain of the Shigella dysenteriae type 7 lipopolysaccharide. Carbohydr. Res., 179, 51-60 (1988).

12) P. B. Helander, L. Kenne, B. Lindberg, K. Peterson, and R. Unger: Structural studies of two capsular polysaccharides elaborated by different strains of Haemophilis infiuenzae type e. Carbohydr. Res., 88, 77-84 (1981).

13) E. Katzenellenbogen, I. Ekiel, and E. Romanowska: The structure of the $O$-specific polysaccharide chain from Citrobacter 023 lipopolysaccharide. Carbohydr. Res., 179, 349357 (1988).

14) P. J. Garegg, P. E. Jansson, B. Lindberg, F. Lindh, J. Lönngren, 1. Kvarunstrom, and W. Nimich: Configuration of the acetal carbon atom of pyruvic acid acetals in some bacterial polysaccharides. Carbohydr. Res., 78, 127-132 (1980).

15) D. Oxley and S. G. Wilkinson: Structural studies of an acidic galactomannan from the reference strain for Serratia marcescens serogroup O4. Carbohydr. Res., 179, 341-348 (1988).

16) C. J. Pouchert: The Aldrich library of NMR spectra (ed. 2, Vol. 1), Aldrich Chemical, Milwaukee, 1983, pp. 485-486.

17) E. Pretsch, T. Clerc, J. Seibl, and W. Simmon: Tabulation of spectral data of organic compounds (translated into Japanese by K. Nakanish), Kodansha, Tokyo, 1982, pp. 95-97.

18) F. P. Tsui, R. Schneerson, R. A. Boykins, A. B. Karpas, and W. Egan: Structural and immunological studies of the Hocmophilts infuenzae type d capsular polysaccharide. Carbohydr. Res., 97, 293-306 (1981).

19) S. F. Osman and W.F. Fett: The structure of the acidic exopolysaccharide of Pseudomonas marginalis strains PF-05-2 and PM-LB-1. Carbohydr. Res., 199, 77-82 (1990).

20) E. Katzenellenbogen, I. Ekiel, and E. Romanowska: The structure of the $\mathrm{O}$-specific polysaccharide chain from Citrobacter O23-lipopolysaccharide. Carbohydr, Res., 179, 349357 (1988). 